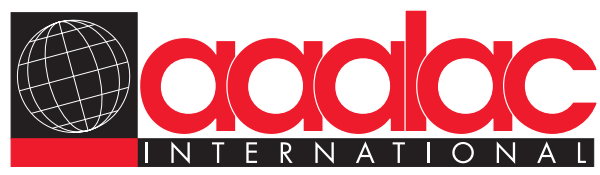

\title{
All the information on animal lab accreditation
}

The Association for Assessment and Accreditation of Laboratory Animal Care (AAALAC) International is a voluntary accreditation and assessment organization in the laboratory animal field. Its international scope is highlighted right at the top of its homepage; the site is available in eight different languages.

The website is filled with information, which users can access through a navigation ribbon located on the left side of all the pages. The 'About AAALAC' page notes that AAALAC International has accredited "more than 900 companies, universities, hospitals, government agencies and other research institutions in 37 countries." The page further explains that AAALAC accreditation, unlike compliance with governmental requirements, is voluntary, but that organizations receiving AAALAC accreditation "are also going the extra step to achieve excellence in animal care and use."

In addition, the 'About AAALAC' page has a long list of frequently asked questions. These address myriad aspects of AAALAC International's functions: how it accredits programs, what is required of programs for accreditation, program review, pharmaceuticals and non-pharmaceuticals that can be used in any laboratory animal research, specific animal research questions, accreditation fees, etc.

But perhaps the most important questions for readers are those dealing with the Council on Accreditation and ad hoc Consultants. The Council on Accreditation is composed of international animal care professionals (most of whom hold advanced veterinary or doctoral degrees) who determine which programs receive AAALAC International accreditation by making site visits and evaluating programs. AAALAC International's Board of Trustees, which is composed of representatives of Member Organizations, the science, professional and educational organizations that make up the membership of AAALAC International, appoints the members of the Council, usually from a pool of ad hoc Consultants and specialists. People wishing to become ad hoc Consultants for AAALAC International must submit an application by 1 February of each calendar year. Applicants come from all over the world, and applications are accepted at AAALAC International's offices in Frederick, MD, US, and Pamplona, Spain. Information on applying to become an ad hoc Consultant is available on the website.

Accreditation begins with evaluation of the applicant organization through use of three primary standards: the 8th edition of the Guide for the Care and Use of Laboratory Animals (the Guide) published by the US National Research Council in 2011, the Guide for the Care and Use of Agricultural Animals in Research and Teaching published by the Federation of Animal Science Societies in 2010 and the European Convention for the Protection of Vertebrate Animals

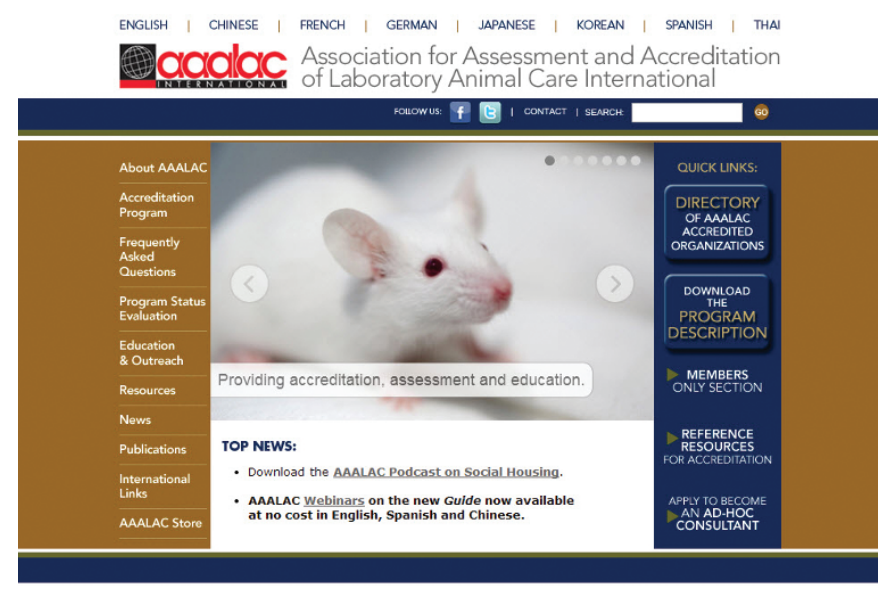

Used for Experimental and Other Scientific Purposes, published by the Council of Europe. The Guide is available in Chinese, Japanese and Thai. A previous edition is available in French, German and Spanish. All of this is explained on the 'Accreditation Program' page of the website.

This page also includes a link to request or download an application for accreditation. The long and detailed application comes with a complex set of instructions. There is a separate application for organizations that are in member countries of the Council of Europe.

The navigation ribbon includes a tab for 'Program Status Evaluation.' This is a special, confidential peer-review program that assesses animal research programs and facilities prior to their application for AAALAC International accreditation. This service aids organizations in understanding what they may need to do to raise their standards to meet AAALAC standards before applying for accreditation.

The 'Education and Outreach' tab brings the visitor to AAALAC's podcast and webinar page. At the time of this review, the first AAALAC podcast - on 'Social Housing' - was available. There are 12 webinars on the site, all related to implementation of the 8 th edition of the Guide. The first is a general webinar related to implementation of the Guide for accreditation. The remaining webinars go into specific chapters of the Guide. Webinars are available in English, Spanish and Chinese.

This is an excellent, informative site, particularly for those who want to learn more about AAALAC accreditation and read more about care of lab animals.

\section{http://www.aaalac.org/}

Content

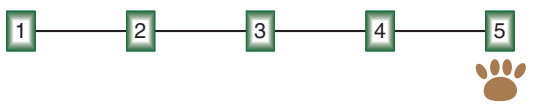

Appearance

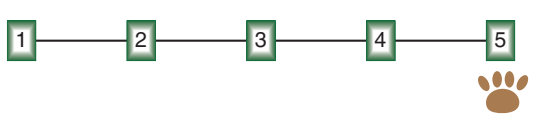

Usability

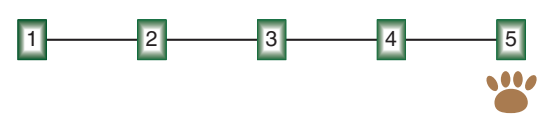

